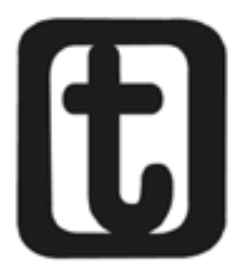

\title{
A IMPORTÂNCIA DA ARTICULAÇÃO ENTRE ABEPSS, CONJUNTO CFESS/CRESS E ENESSO PARA A CONSTRU- ÇÃO DO PROJETO ÉTICO-POLÍTICO DO SERVIÇO SOCIAL BRASILEIRO
}

The importance of interaction between Abepss, CFESS/Cress and Enesso for building the Brazilian Social Work Ethical-Political Project

\section{Sâmya R. Ramos ${ }^{1}$}

A Associação Brasileira de Ensino e Pesquisa em Serviço Social (Abepss) comemora, em 2011, 65 anos de existência e, nos últimos 32 anos, vem desenvolvendo um rico processo de articulação com as demais entidades representativas da categoria. A ação política da Abepss, do Conjunto Conselho Federal de Serviço Social/Conselhos Regionais de Serviço Social e da Executiva Nacional dos Estudantes de Serviço Social (CFESS/Cress e Enesso) é um elemento fundante para a manutenção do projeto ético-político do Serviço Social no Brasil, na medida em que um projeto profissional que objetiva a realização e ampliação de direitos só se mantém se contar com uma base social de sustentação política, o que coloca a práxis política como o meio adequado à sua realização (BARROCO, 1999).

\footnotetext{
${ }^{1}$ Assistente social (Universidade Estadual do Ceará). Doutora em Serviço Social pela Universidade Federal de Pernambuco (2005). Professora da Universidade do Estado do Rio Grande do Norte e professora colaboradora do Mestrado de Serviço Social da Universidade Federal do Rio Grande do Norte. Presidente do Conselho Federal de Serviço Social (gestão TEMPO DE LUTA E RESISTÊNCIA 2011-2014). E-mail: <samya@cfess.org.br>.
} 
Tais entidades materializam uma ação política que é um dos fatores que garantem a possibilidade de manutenção da direção social deste projeto coletivo que se vincula a um projeto societário comprometido com o fim da exploração/dominação dos seres humanos, ou seja, com a emancipação humana.

A Abepss (ao coordenar o debate sobre o projeto de formação profissional), o Conjunto CFESS/Cress (entidade responsável pela fiscalização do exercício profissional) e a Enesso (que dirige a mobilização do Movimento Estudantil de Serviço Social) têm se constituído, portanto, em locus de debates teórico-políticos e lutas que põem em cena os limites e contradições da ordem do capital, contribuindo, dessa forma, para a construção do projeto ético-político profissional, hegemônico no Serviço Social brasileiro.

A respeito da articulação entre as entidades representativas da categoria, é ilustrativo o Relatório Final da gestão 93-95, da Associação Brasileira de Ensino e Pesquisa em Serviço Social/Centro de Documentação e Pesquisa em Políticas Sociais e Serviço Social (Abepss/Cedepss), apresentado na XXIX Convenção Nacional, em 1995, ao enfatizar que

Papéis relevantes foram desempenhados pela ENESSO e pelo CFESS. A ENESSO, particularmente, através de sua secretaria de formação profissional, realizou grandes investimentos teórico-políticos na ampliação e aprofundamento do debate. Como parceira da ABESS no processo de construção da hegemonia que define a direção social e política da formação profissional, a ENESSO, coordenadora da participação do Movimento Estudantil, torna-se presença importante necessária. No âmbito do exercício profissional e da organização da categoria, o CFESS constitui-se incentivador e co-participante da direção construída neste percurso (ABEPSS/CEDEPSS, 1995).

A articulação entre essas entidades e o nível de organização dos segmentos profissional e estudantil é referendada como um patrimônio político, historicamente conquistado na profissão e que contribui efetivamente para a construção de uma cultura política democrática no âmbito do Serviço Social. 
Esta articulação se processou, nas últimas três décadas, em vários momentos, com destaque para: a organização conjunta de eventos, dentre os quais ressaltamos o Congresso Brasileiro em Assistência Social (CBAS).

Como exemplo, podemos citar os três CBAS, realizados nos anos $1990^{2}$, que atestam a maturidade política e acadêmica alcançada pela categoria a partir dos acúmulos da década anterior, sendo caudatários do significado histórico do Congresso da Virada de 1979.

Sobre o VIII CBAS, realizado em 1995 na Bahia, ressalte-se o grande significado pelo seu caráter político em face às expressões concretas do projeto neoliberal na vida dos(as) trabalhadores(as) e, particularmente, nas condições de trabalho dos(as) assistentes sociais. A radicalidade do evento ficou explícita pelas temáticas abordadas, que demonstravam a necessidade de se discutir a disputa entre os projetos societários, além do feito histórico de reunir um grande contingente de profissionais de uma categoria se contrapondo ao posicionamento do projeto neoliberal em relação às políticas públicas e às condições de vida das classes trabalhadoras (MATOS, 2003).

Analisando os trabalhos apresentados nesses congressos, através dos títulos e conteúdos presentes nos anais destes eventos, encontramos um reduzido número deles sobre a temática da organização política dos(as) assistentes sociais e suas entidades representativas nacionais ${ }^{3}$ (RAMOS, 2005).

Isso se modifica um pouco no X CBAS, realizado no Rio de Janeiro, em 2001, no qual foi apresentado um maior número de trabalhos

\footnotetext{
${ }^{2}$ Foram os seguintes os CBAS promovidos na década de 1990: VII CBAS - maio/1992, em São Paulo (SP) - Tema: Serviço Social e o desafio da 'modernidade': os projetos sociopolíticos em confronto na sociedade contemporânea; VIII CBAS - julho/1995, em Salvador (BA) - Tema: "O Serviço Social frente ao projeto neoliberal: em defesa das políticas públicas e da democracia"; IX CBAS - julho/1998, em Goiânia (GO) - Tema: Trabalho e projeto ético-político profissional.

3 São os seguintes os trabalhos elaborados sobre essas temáticas: VII CBAS: Refletindo sobre a organização dos assistentes sociais; Os desafios dos Congressos Brasileiros de Assistentes Sociais - a propósito do III e do VII; VIII CBAS: Análise do discurso da Associação Brasileira de Ensino de Serviço Social; Desvendando os limites da profissão; O novo brotando do velho ou extinção da ANAS; IX CBAS: A inserção política dos assistentes sociais nos rumos de uma nova sociedade; Cress itinerante: uma experiência de socialização do código de ética em Alagoas.
} 
que analisam aspectos da organização política dos(as) assistentes sociais ${ }^{4}$.

Além dos CBAS, foi realizado, conjuntamente pelas três entidades, o Encontro Nacional de organização da categoria Serviço Social e o Projeto Político Profissional - Rumo ao Século XXI, em Brasília, em 1997. O Encontro contemplou os debates da categoria no Brasil frente à reestruturação produtiva e à reforma do Estado. A partir das reflexões sobre o assistente social enquanto trabalhador e sujeito político, foram problematizados os dilemas do Projeto Ético-Político profissional, a organização sindical, a formação profissional e o movimento estudantil, tendo sido possível discutir estratégias e mecanismos para fortalecer a organização desta categoria no Brasil.

Outra frente de intervenção das entidades da categoria tem sido a formação profissional. Neste sentido, o CFESS, a Abepss e a Enesso têm se articulado em favor da defesa: das diretrizes curriculares; da qualidade dos cursos de graduação e pós-graduação; da indissolubilidade entre ensino, pesquisa e extensão; da articulação entre formação e exercício profissional do(a) assistente social; enfim, da defesa do projeto de formação construído coletivamente pela categoria profissional, que teve como marco o Currículo Mínimo de 1982. Por outro lado, as entidades têm se posicionado contrárias a várias questões, tais como: exame nacional de cursos (provão); mestrados profissionalizantes; cursos sequenciais e a graduação a distância em Serviço Social.

Em relação à luta contra o Ensino à Distância (EAD) na graduação em Serviço Social, várias atividades foram realizadas em conjunto pelas três entidades nacionais, em 2011, com destaque para a campanha Educação não é fast-food: diga não à graduação a distância no Serviço Social e o Seminário nacional em defesa da educação com

\footnotetext{
4 São os seguintes os trabalhos: A organização política dos(as) assistentes sociais e a construção do projeto ético-político profissional: sinalizando horizontes; Projeto Ética em Movimento - realizado na $1^{\mathrm{a}}$ etapa de multiplicação pelo Cress $12^{\mathrm{a}}$; Mobilização política dos assistentes sociais: um desafio para os Cress; Algumas considerações sobre o posicionamento ético-político do Conjunto CFESS/Cress frente às novas demandas na profissão; $A$ organização sindical dos assistentes sociais - uma transitoriedade inconclusa; O processo formativo do assistente social frente ao espaço coletivo do movimento estudantil de Serviço Social; Os assistentes sociais e a organização sindical (CD-ROM do $10^{\circ} \mathrm{CBAS}$ ).
} 
qualidade: a graduação a distância em debate, em conjunto com o Andes.

A referida campanha expressa o compromisso das entidades com a educação superior pública, gratuita, laica e de qualidade

\begin{abstract}
[...] voltada para atender às necessidades da população brasileira e enfrentar a precarização e mercantilização das políticas sociais, bem como as desigualdades no país. Essa bandeira de luta histórica é também de um conjunto de movimentos sociais que, ao incorporá-la, evidencia que a graduação com qualidade e gratuidade não se coaduna com os cursos de graduação a distância (CONSELHO FEDERAL DE SERVIÇO SOCIAL, 2011a).
\end{abstract}

Tais propostas inserem-se na perspectiva de fortalecer movimentos de resistência à privatização do ensino superior na perspectiva da defesa da educação como direito.

Estas ações foram planejadas pelo Grupo de Trabalho (GT) trabaIho e formação profissional composto por conselheiras do CFESS, de 5 Cress, da Abepss e da Enesso. O referido GT iniciou, em 2008, o trabalho de sistematização de estratégias de enfrentamento à precarização do ensino superior, tendo como principais atribuições: sistematizar atividades já realizadas pelas entidades nacionais do Serviço Social, bem como construir novas estratégias de enfrentamento à precarização do ensino superior e subsidiar a realização de ações coletivas em defesa da formação e do exercício profissional com qualidade.

Merece destaque a elaboração, em 2008, do Plano Nacional de Lutas em Defesa da Formação e do Trabalho Profissional, para ser materializado em conjunto pelas três entidades nacionais - CFESS, Abepss e Enesso - com o objetivo de contribuir para gestar uma grande mobilização nacional do Serviço Social em torno da qualificação do trabalho e da formação profissionais. Constam no Plano os seguintes eixos: de ações relativas à política nacional de fiscalização; de ações de estudos e pesquisas; de ações de articulação com entidades, movimentos sociais e conselhos; de ações junto 
ao MEC; de ações junto ao poder legislativo; de ações jurídicas e de ações de comunicação e mobilização (CONSELHO FEDERAL DE SERVIÇO SOCIAL, 2011b).

Outra iniciativa relevante no âmbito da articulação entre as entidades é a celebração de convênios em razão de projetos comuns entre o CFESS e as outras duas entidades, visando à realização de atividades da Abepss e Enesso. Algumas vezes esses convênios são materializados por meio de apoio financeiro.

Essa cooperação do CFESS em relação à Abepss e à Enesso demonstra uma solidariedade em torno de um projeto político comum. Como expressões vivas do dinâmico processo de organização política da categoria, as entidades colaboram umas com as outras em diversos aspectos, sendo o financeiro um dos elementos centrais para viabilização das suas atividades. O CFESS, como entidade que mais arrecada, via pagamento das anuidades dos(as) profissionais inscritos(as), contribuía, com as demais entidades, de forma esporádica e, com o advento dos convênios, essa colaboração tornou-se mais sistemática, tendo por base o planejamento para realização de atividades conjuntas.

Com relação à Abepss, o CFESS estabeleceu convênios para fazer os cursos de especialização a distância5. Outros convênios foram estabelecidos entre as duas entidades com o objetivo de materializar o plano de lutas, construído desde 2008, contribuindo para a realização de eventos regionais que debateram a Política Nacional de Estágio (gestão Abepss 2009/2010) e irão viabilizar o projeto Abepss itinerante (gestão Abepss 2011/2012).

Os convênios que foram firmados entre o CFESS e a Enesso tiveram por objetivo incentivar a formação política dos(as) dirigentes estudantis, contribuindo, assim, no desenvolvimento de futuros dirigentes profissionais. O convênio prevê um repasse financeiro do CFESS para a Enesso, com o intuito de custear passagens para viabilizar a presença dos(as) dirigentes da entidade nacional repre-

${ }^{5}$ Foram organizados dois Cursos de Especialização a distância: Serviço Social e Política Social, em 1999/2000, e Serviço Social: direitos sociais e competências profissionais, em 2009/2010, em parceria da Abepss com o CFESS. 
sentativa dos(as) estudantes em fóruns do Movimento Estudantil de Serviço Social.

Os convênios firmados entre as entidades expressam a solidariedade entre elas na questão financeira, tendo como norte a construção de ações que fortaleçam o projeto ético-político profissional, além de terem propiciado a formalização das atividades, dando mais transparência e visibilidade para essa relação em torno de projetos comuns.

É importante destacar que tal articulação entre o exercício profissional, a formação profissional e os estudantes é uma particularidade da organização política do Serviço Social brasileiro. Os estudantes, por exemplo, não são considerados, em muitos países, partícipes das articulações profissionais como o são no Brasil, onde organizam eventos, participam de campanhas e elaboram documentos em conjunto com as demais entidades representativas da categoria.

Nesse sentido, o segmento estudantil é considerado como sujeito fundamental do processo de organização política da categoria dos(as) assistentes sociais, no Brasil. Considerados como profissionais em formação, são incluídos, pelos demais segmentos da profissão, no processo de articulação e mobilização do Serviço Social.

Nessa direção, a organização estudantil tem participado, principalmente, através da sua entidade nacional, do processo de organização da categoria, a partir do final de década de 1980, com a criação da entidade nacional dos(as) estudantes de Serviço Social: a Subsecretaria de Estudantes de Serviço Social na União Nacional dos Estudantes (Sessune), que, em 1993, passou a denominar-se de Enesso (Executiva Nacional dos Estudantes de Serviço Social). No processo de construção da sua ação política, a Enesso tem participado ativamente nos debates coletivos gestados na profissão. Nota-se a participação estudantil em todos os momentos decisivos para os rumos do Serviço Social brasileiro, notadamente nesta década, como se observa nos documentos produzidos sobre a dinâmica de elaboração do código de ética de 1993 e das diretrizes curriculares de 1996. 
É interessante ressaltar que o Movimento Estudantil (ME) se estabelece como uma arena de formação política da maioria dos(as) futuros(as) dirigentes profissionais que irão atuar na Abepss e no Conjunto CFESS/Cress. Enquanto movimento social com base social transitória, o ME é um locus, muitas vezes, de iniciação de parcelas da juventude na militância política, se configurando como um espaço de formação político-ideológica de militantes que, depois, irão atuar em outras esferas organizativas. O ME de Serviço Social, em particular, vem desenvolvendo esse importante canal de capacitação de militantes políticos que, ao saírem da graduação, continuam participando de outras entidades da categoria ou em outros espaços organizativos.

Essa relação da Enesso com a Abepss e o CFESS enriquece o contato do segmento estudantil com a realidade da formação e do exercício profissional, através da participação conjunta em eventos, atividades e lutas coletivas, em cujos acontecimentos pauta-se a defesa de condições dignas para a materialização de uma formação e de um trabalho com qualidade.

Os conflitos também podem aparecer em alguns momentos na relação entre as entidades, pois comparecem, neste processo, diferentes forças políticas nas direções das entidades e, por vezes, surgem divergências e dificuldades nas articulações entre as entidades nacionais. A relação entre as entidades não está isenta de tensões e conflitos. Vários requisitos contribuem para um andamento satisfatório dessa parceria, com destaque para: a defesa comum dos princípios do projeto profissional; o respeito e a confiança mútua, mesmo em meio a algumas divergências e ao cumprimento dos acordos e negociações feitos em torno de projetos comuns. Os(as) militantes, mediadores(as) da relação entre as entidades, podem facilitar ou dificultar esse processo de construção coletiva, a depender de como encaminhem política e subjetivamente as atividades e relações conjuntas.

Esta construção conjunta entre a Abepss, o Conjunto CFESS/Cress e a Enesso requisita, cotidianamente, que tais entidades representativas sejam 
[...] capazes de abraçar, no seu interior, diferentes correntes intelectuais e políticas em disputa no âmbito profissional, sem abrir mão dos compromissos ético-políticos que dão o norte à profissão. Enfim, entidades legítimas, fruto do amplo desenvolvimento da categoria na trajetória de suas lutas e na formulação de respostas técnico-políticas às transformações societárias, contribuindo para o redimensionamento da profissão na contemporaneidade (IAMAMOTO, 1999, p.148).

As entidades representativas dos(as) assistentes sociais brasileiros vêm construindo sua organização política, no contexto atual, na perspectiva de estabelecer uma práxis política emancipatória, nos limites da sociabilidade do capital - em uma conjuntura de crise dos projetos societários emancipatórios; de refluxo dos Movimentos Sociais; de pauperização e desemprego da classe trabalhadora. A ação política destas entidades tem se constituído em um dos fatores que garantem a possibilidade de manutenção da direção social do projeto profissional vinculada aos interesses do trabalho (RAMOS, 2006).

\section{REFERÊNCIAS}

ABEPSS;CEDEPSS. Relatório Final da gestão 93-95. 1995.

BARROCO, Lúcia. Os fundamentos sócio-históricos da ética. In: CFESS. Curso de Capacitação em Serviço Social e Política Social: módulo II. Brasília: CEAD,1999.

CONSELHO FEDERAL DE SERVIÇO SOCIAL (Brasil). CFESS Manifesta "Educação não é fast-food". Brasília, $2011 a$.

. Plano de lutas em defesa do trabalho e da formação e contra a precarização do ensino superior. Brasília: CFESS, GT trabalho e formação profissional, 2011b. Disponível em: <www.cfess.org.br/ arquivos/Plano-de-Lutas-atualizado-maio-2011.pdf $>$. 
IAMAMOTO, M. V. O Serviço Social na contemporaneidade: trabaIho e formação profissional. São Paulo: Cortez, 1999.

MATOS, M. C. de. O debate do Serviço Social na saúde nos anos 90. Serviço Social e Sociedade, São Paulo, n. 74, 2003.

RAMOS, S. R. A mediação da organização política na (re)construção do projeto profissional: o protagonismo do Conselho Federal de Serviço Social. Recife, 2005. Tese (Doutorado) - Pós-Graduação de Serviço Social, Universidade Federal de Pernambuco.

. Organização política dos(as) assistentes sociais brasileiros(as): a construção histórica de um patrimônio coletivo na defesa do projeto profissional. Serviço Social e Sociedade, São Paulo, n. 88, 2006. 